\title{
Comparative studies on the roles of calcium ions and gap Junctions in the regulation of secretory and contractile processes: Biochemical and pharmacologic approaches
}

\author{
Viktor I Goudochnikov* \\ ${ }^{1}$ Council of International Society for DOHaD, Brazil
}

\begin{abstract}
This article presents a review of our own studies on the role of calcium ions and gap junctions in the regulation of prolactin and growth hormone secretion by rat adenohypophyseal cells in primary cultures. The article reviews also our own data on interactions of calcium ions with functional activity of gap junctions in the regulation of contractions of isolated rat uterus. The discussion is presented of literature evidence on the role of gap junctions in the regulation of insulin secretion by pancreatic islets and contractions of vascular smooth muscle tissues, as well as on the perspectives of studying the contribution of gap junctional intercellular communication in the framework of DOHaD (Developmental Origins of Health and Disease). Finally the article considers briefly the elaboration and possible use of pharmacologic agents modulating functional activity of gap junctions in the treatment of several diseases.
\end{abstract}

\section{Introduction}

This article has rather long history lasting for almost 40 years. In fact, already in the eighties and nineties of the last century we studied the roles of calcium ions $\left(\mathrm{Ca}^{2+}\right)$ and gap junctions in the regulation of prolactin (PRL) and growth hormone $(\mathrm{GH})$ secretion by rat adenohypophyseal cells in primary cultures [1-8]. Somewhat later we applied similar approaches for studying the roles of calcium ions and gap junctions in the regulation of contractile activity of isolated rat uterus $[9,10]$. Although many years have passed from that period, these data have not lost their significance and in addition, practically nobody has tried to perform comparative analysis of the roles of calcium ions and gap junctions in the regulation of secretory and contractile processes. We have decided to fill this gap, reviewing our own data on PRL and GH secretion by adenohypophyseal cells and our results on contractile activity of isolated rat uterus. Finally, we shall discuss literature evidence on the role of gap junctions in regulation of insulin secretion by beta-cells of pancreatic islets and contractile activity of vascular smooth muscle tissues, in order to compare our own data with bibliographic evidence obtained on other experimental models, evaluating other secretory and contractile processes.

The role of calcium ions and gap junctions in the regulation of prolactin and growth hormone secretion

First of all, our experiments performed on primary cultures of rat adenohypophyseal cells have shown that removal of calcium ions from the incubation medium resulted in the decrease of basal PRL secretion, but did not change basal GH release. However, in the medium without calcium ions, the stimulatory influence of depolarizing concentrations of potassium $\left(\mathrm{K}^{+}\right)$ions $(30$ or $55 \mathrm{mM}$ ) on both $\mathrm{PRL}$ and $\mathrm{GH}$ release was completely prevented $[1,2]$. We have established also that ions of cobalt $\left(\mathrm{Co}^{2+}\right)$, the antagonist of calcium ions, inhibited PRL secretion, whereas ions of barium $\left(\mathrm{Ba}^{2+}\right)$, considered to be an agonist of calcium ions, stimulated PRL and GH release, and in the medium without calcium ions these effects of $\mathrm{Ba}^{2+}$ were greatly enhanced $[2,3]$. Finally, we have observed that in the medium without calcium ions, the stimulatory action of thyroliberin (TRH) on PRL secretion was decreased, whereas, in contrast, it was necessary to add the excess of calcium ions (5 mM) to incubation medium, in order to prevent the inhibitory influence of somatostatin on PRL and GH release [4,5].

Already in the decade of nineties of the last century we have observed in the experiments on primary cultures of rat adenohypophyseal cells that octanol, a pharmacologic agent blocking gap junctions, did not influence basal PRL secretion, but inhibited PRL release stimulated by TRH or dibutyryl-derivative of cyclic AMP (DbcAMP) [6-8]. In addition, octanol did not influence basal GH secretion, as well as GH release stimulated by dibutyryl-derivative of cyclic GMP, but this agent inhibited GH release stimulated by TRH or DbcAMP $[7,8]$.

In conclusion, we can affirm that calcium ions and gap junctions play very important and quite selective roles in the regulation of secretory processes in anterior pituitary.

Interrelated roles of calcium ions and gap junctions in the regulation of contractile activity of isolated rat uterus

In the experiments on adult rat uterus $[9,10]$, we have established that in the incubation medium with $1-2 \mathrm{mM} \mathrm{Ca}^{2+}$, gap junctionblocking agent octanol, already in the concentration of $0.3 \mathrm{mM}$,

${ }^{\star}$ Correspondence to: Viktor I. Goudochnikov, Council of International Society for DOHaD, Rua Matoso Camara 73, CEP 97050-500, Santa Maria - RS, Brazil, E-mail: victorig40@hotmail.com

Key words: calcium ions, gap junctions, adenohypophysis, uterus, octanol

Received: February 19, 2019; Accepted: March 05, 2019; Published: March 09, 2019 
Goudochnikov VI (2019) Comparative studies on the roles of calcium ions and gap Junctions in the regulation of secretory and contractile processes: Biochemical and pharmacologic approaches

inhibited uterine contractions induced by oxytocin, however in the medium with excess $\mathrm{Ca}^{2+}(5 \mathrm{mM})$ or in the cases of elevated oxytocin concentrations, higher level of octanol $(0.6 \mathrm{mM})$ was necessary for inhibition of oxytocin-induced uterine contractile activity.

Similar situation was observed in relation to acetylcholine (ACh), i.e. with the increase of concentration of this neurotransmitter, parallel augment of octanol level was necessary for inhibiting the contractions of adult rat uterus. On the other hand, in the case of intermediate ACh concentration, it was possible to prevent inhibitory octanol action by means of addition of $\mathrm{Ca}^{2+}$ excess to incubation medium. Similar peculiarities were observed also in the experiments on the uterus of adult rats with depolarizing concentration of potassium ions $(29 \mathrm{mM})$, i.e. the addition of $\mathrm{Ca}^{2+}$ excess to incubation medium decreased the inhibitory octanol action on stimulated uterine contractions.

In the experiments on the uterus of adult rats we have shown the inhibitory influence of verapamyl, the antagonist of calcium channels, on uterine contractions induced by depolarizing concentration of potassium ions $(29 \mathrm{mM})$ or by $\mathrm{ACh}$. We have performed also the comparison of inhibitory actions of verapamyl, octanol and adrenaline on uterine contractions induced by $\mathrm{ACh}$ or $\mathrm{Ba}^{2+}(1 \mathrm{mM})$. Moreover, it was demonstrated that the addition of $\mathrm{Ca}^{2+}$ excess to incubation medium dose-dependently blocked the actions of all three inhibitors of contractions of adult rat uterus (verapamyl, octanol and adrenaline).

Several experiments were performed on isolated uterus of prepubertal rats. In particular, it was found that addition of $\mathrm{Ca}^{2+}$ excess to incubation medium was able to partially counteract inhibitory octanol influence on uterine contractions caused by depolarizing concentration of potassium ions $(54 \mathrm{mM})$. Similar situation was observed in experiments on the uterus of prepubertal animals also in the case of uterine contractions induced by $\mathrm{Ba}^{2+}$.

Therefore, summarizing the facts described above, we can conclude that octanol, i.e. the agent blocking gap junctions, dose-dependently inhibited contractile activity of isolated uterus of adult rats, whereas $\mathrm{Ca}^{2+}$ excess in the incubation medium dose-dependently prevented this inhibitory octanol action, i.e. the action of octanol combined with $\mathrm{Ca}^{2+}$ is similar to the effects of other inhibitors of uterine contractions, verapamyl and adrenaline, combined with $\mathrm{Ca}^{2+}$. In addition, the interaction of octanol and $\mathrm{Ca}^{2+}$ excess was partially demonstrated also on isolated uterus of prepubertal animals.

\section{The role of gap junctions in regulation of other secretory and contractile processes}

The literature search was obviously realized before performing our experiments in the decades of eighties and nineties of the last century. Moreover, this bibliographic search was performed recently once more. In present article we shall limit the discussion by describing literature evidence on insulin secretion and contractile activity of vascular smooth muscle tissues.

The most important contribution to studies on the role of gap junctions in the regulation of insulin secretion was made by Swiss research group of Paolo Meda [11]. These investigators have shown, in particular, that heptanol, i.e. an agent similar to octanol in its capacity of blocking the gap junctions, inhibited insulin secretion by pancreatic islets, stimulated by high glucose concentrations, and this effect was totally reversible after removal of heptanol from incubation medium. It is interesting that heptanol did not cause any influence on insulin secretion by isolated, single beta-cells of pancreatic islets, i.e. for realization of inhibitory heptanol action, the presence of intercellular gap junctions was absolutely necessary.

On the other hand, inhibitory heptanol and octanol influence on contractile activity of smooth muscle tissues was shown in experiments on isolated aorta or mesenteric vascular preparations [12-14], however none of these works attempted to study combined effects of gap junction blockers and $\mathrm{Ca}^{2+}$ excess in the incubation medium.

\section{General discussion of our own results and literature data}

One of the most active authors in studying the gap junctions, James E. Trosko has written recently in his review article that unfortunately, during the last decades biomedical researchers in the whole world largely ignored this important theme [15]. We completely agree with this critical notion, confirming for example, the scarcity of investigations on the role of gap junctions in the regulation of contractile uterine activity after a series of electron-microscopic studies of Canadian group of R.E. Garfield in the eighties of the last century [16] and after our results on effects of octanol, although already in 1996 we were able to attract the attention to them of Juan Saez, well-known researcher of gap junctions during Pan-American Congress of Biochemistry and Molecular Biology in Chile.

Nevertheless, certain progress in understanding the role of gap junctions in regulation of secretory and contractile processes was achieved in general during the last decades. In fact, soon after publication of our works on PRL and GH secretion, it was established that in rat anterior pituitary in vivo and in primary culture of adenohypophyseal cells, the gap junctions were revealed, first of all, between so called folliculo-stellate cells and lactotrophs or somatotrophs, i.e. the cells secreting PRL and GH respectively [17]. By the way, significant participation of folliculo-stellate cells and intercellular communication mediated by gap junctions are forcing us to introduce certain corrections to our theoretical model of anterior pituitary cytoarchitectonics on the basis of cell flows [18,19].

In addition, the advances in studying the connexins, i.e. proteins representing the principal component of gap junctions, have resulted in the identification of important differences between endocrine glands containing the connexin with calculated molecular mass of 43 kilodalton $(\mathrm{Cx} 43)$ and exocrine glands containing Cx32 [20]. Quite interesting aspect consists of the evidence that agents activating exocrine secretion of amylase and other enzymes by acinar pancreatic cells, do not stimulate, but really inhibit functional activity of their gap junctions, whereas heptanol, i.e. the blocker of gap junctions, stimulates exocrine activity of acinar pancreatic cells.

Although, on our opinion, it is too early to make significant conclusions on this basis, we consider to be quite appropriate in offering preliminary suggestion that such difference in the contribution of gap junctions to regulation of endocrine and exocrine secretion may be partially related to the necessity of higher stimulation of at least some endocrine glands during the phase of active functionality of the organism (or stress) and on the contrary, higher stimulation of exocrine secretion in the phase of relative rest of the body that in turn, depends on the balance of activities of sympathetic and parasympathetic parts of autonomic/ vegetative nervous system.

Although in the eighties of the last century we could not study the role of gap junctions in the regulation of functional activities of cultured rat liver cells by means of evaluating the effects of octanol, nevertheless it continues to be not clarified, why DbcAMP in certain doses and incubation durations did not stimulate, but really inhibited both the 
Goudochnikov VI (2019) Comparative studies on the roles of calcium ions and gap Junctions in the regulation of secretory and contractile processes: Biochemical and pharmacologic approaches

secretion of serum albumin and total RNA and protein biosynthetic rates in cultured hepatocytes $[21,22]$. It is possible that partially the answer to this question can be given, considering that in accord with its secretory function, the liver is much more similar to exocrine glands, since this organ is secreting bile to the lumen of intestinal tract, whereas the secretion of albumin and other blood serum proteins by hepatocytes is radically different in its mechanisms from the release of e.g., pituitary hormonal proteins.

\section{Conclusion}

Already in 1990 we have tried to attract the attention to gap junction theme, suggesting the possible participation of so called intercrine, or intercellular signaling communication in the regulation of various physiologic processes [23]. In fact, at that time and until present moment the researchers usually considered to greater extent the extracellular and intracellular types of signaling communication, where the principal role are played respectively by hormones and other bioactive substances transported by blood and other biological fluids and by so called secondary messengers of hormonal signals, destined for acting inside the cells (cyclic nucleotides, calcium ions, etc.) [15].

Nevertheless, it was shown already in the experiments on paired cardiomyocytes that cAMP and angiotensin II generated inside the cells, are able to participate in the transfer of regulatory signals through gap junctions to neighbor cells $[24,25]$. In addition, the oscillations of intracellular $\mathrm{Ca}^{2+}$ concentration can be propagated along the tissues and in cell cultures by means of gap junctions [26], in spite of the fact that in high concentrations $\left(>10^{-5} \mathrm{M}\right)$ the same calcium ions are able to shut down the gap junctions. Perhaps, exactly the last fact found already in the sixties of the last century [27], has delayed to certain extent the studies of interactions between calcium ions and gap junctions in the regulation of physiologic processes, although already in the original works of the sixties and later on it was frequently noted that such influence of high intracellular $\mathrm{Ca}^{2+}$ concentrations is necessary for preventing the transfer of lesions from cells with disrupted integrity of cytoplasmic biomembrane to the neighbor cells.

Therefore, summarizing all described above, it is possible to make a conclusion that there exists really essential similarity in the contribution of calcium ions and gap junctions to the regulation of at least some secretory and contractile processes. Many authors explain such similarity in the following manner: for attaining sufficient intensity of hormone release to the blood or contraction of smooth muscle tissues, it is necessary to achieve the combined and synchronized activation of functional activity of separate cells interconnected by means of gap junctions between them [28]. It is important also that gap junctions are necessary probably for enhancing the sensitivity of endocrine organs and smooth muscle tissues to natural bioregulators and pharmacologic agents [12]. It means that together with calcium ions, intercellular communication by means of gap junctions plays very important roles in regulation of various secretory and contractile processes.

The question about changes of intercellular communication mediated by gap junctions in the ontogeny remains poorly explored. Somewhat recently James E. Trosko [15] tried to find the connection between the phenomena of programming / imprinting in the framework of $\mathrm{DOHaD}$ concept and alterations of gap junctions during cell differentiation, but in general, this important question remains completely open for future studies. Earlier we have investigated possible differences in the role of calcium ions and cyclic nucleotides in cultured anterior pituitary cells of rats of different age groups [29], and in experiments on isolated rat uterus we have made an attempt of comparing the role of gap junctions in regulation of contractile uterine activity, depending on the extent of maturity of this organ (see above). Without any doubt, these interesting studies should be continued. Especially important seems to be the question about participation of serotonin and other compounds with low molecular weight, capable to penetrate through gap junctions, in embryogenesis [30].

In conclusion, we would like to note that there is significant, but still latent potential in elaborating new pharmacologic agents influencing gap junctions [31]. This notion is confirmed by experimental works evidencing the potential capacity of heptanol or octanol to limit cellular lesions in ischemic heart disease and epilepsy [32,33]. There is the necessity of more intense investigations on the role of gap junctions in heart failure [34] and carcinogenesis [15]. Therefore, on our opinion, the biochemists, pharmacologists, and other investigators in biomedical sciences cannot ignore, no more, the gap junction theme.

\section{Acknowledgment}

This article is dedicated to memory of the late Moscow colleagues and friends: MD, endocrinologist Igor S. Komolov that has given invaluable help on the first steps of working with primary cultures of adenohypophyseal cells, and $\mathrm{PhD}$, a specialist in biophysics, Alexandre B. Timofeyev that has attracted an attention to quite interesting theme of gap junctions.

In addition, the author is grateful to Prof. Sergio L. Dalmora (Dept. of Industrial Pharmacy, UFSM, Brazil) for the opportunity of using the apparatus of isolated rat uterus for studying the octanol effects.

\section{Financial support}

This bibliographic work has been performed according to personal initiative and without financial support from any source. However, during realization of experiments on pituitary cell cultures and isolated rat uterus the author was partially supported respectively by Academy of Medical Sciences (Moscow, Russia), together with Institute of Experimental Medicine (Budapest, Hungary) and by CNPq, together with UFSM (Santa Maria - RS, Brazil).

\section{References}

1. Gudoshnikov VI, Komolov IS, Fedotov VP (1980) [Role of calcium and potassium in regulating prolactin and somatotropic hormone release in cell cultures of rat adenohypophysis]. Vopr Med Khim 26: 525-528. [Crossref]

2. Gudoshnikov VI (1980) [Regulation of prolactin secretion in primary cultures of adenohypophyseal rat cells]. Moscow: $\mathrm{PhD}$ Thesis in Biochemistry (in Russian).

3. Rappay G, Komolov IS, Fazekas I, Bacsy E, Gudoshnikov VI, et al. (1981) Ba2+ affects growth hormone and prolactin secretion, as well as cell morphology in rat anterior pituitary cultures. Acta Biol Acad Sci Hung 32: 137-146. [Crossref]

4. Gudoshnikov VI, Komolov IS, Fedotov VP (1981) Interaction of calcium and somatostatin in the control of prolactin and somatotropin release from a primary culture of rat adenohypophyseal cells. Neurosci Behav Physiol 11: 440-442. [Crossref]

5. Komolov IS, Fedotov VP, Gudoshnikov VI, Fazekas I, Rappy G (1982) Calcium modifies the effects of thyroliberin and somatostatin on hormone release from cel cultures of the rat anterior pituitary. Endokrinologie (Leipzig) 80: 318-324. [Crossref]

6. Gudoshnikov VI, Fedotov VP (1992) [The role of gap junctions in the regulation by cyclic AMP of prolactin secretion and total protein biosynthesis in primary cultures of rat pituitary cells]. Doklady Akad. Nauk 327: 581-583 (in Russian). [Crossref]

7. Fedotov VP, Gudoshnikov VI, Baranova IN (1993) Possible involvement of gap junctions in realizing effects of stimulators of secretory processes in the pituitary. Biull Eksp Biol Med 116: 1523-1525. [Crossref]

8. Fedotov VP, Goudochnikov VI (1994) Putative role of gap-junctional communication between rat pituitary cells in the control of prolactin and growth hormone secretion. Cell Biol Int 18: 533. 
Goudochnikov VI (2019) Comparative studies on the roles of calcium ions and gap Junctions in the regulation of secretory and contractile processes: Biochemical and pharmacologic approaches

9. Goudochnikov VI (1996) Effects of octanol on uterine contractions ex vivo reveal possible interactions of gap-junctional intercellular communication and regulation of calcium fluxes in rat myometrium. In: 5. Congresso Brasileiro de Biomedicina. Sao Paulo: 23.

10. Goudochnikov VI, Dalmora SL (1996). Effects of octanol on secretory and contractile functions reveal possible interactions between second messengers and gap-junctional intercellular communication. In: 8. PABMP Congress. Noticiero de Biologia (Santiago, Chile) 4 .

11. Meda P, Bosco D, Chanson M, Giordano E, Vallar L, et al. (1990) Rapid and reversible secretion changes during uncoupling of insulin-producing cells. J Clin Invest 86: 759768. [Crossref]

12. Christ GJ, Brink PR, Zhao W, Moss J, Gondré CM, et al. (1993) Gap junctions modulate tissue contractility and alpha1 adrenergic agonist efficacy in isolated rat aorta. J Pharmacol Exp Ther 266: 1054-1065. [Crossref]

13. Georgescu A, Alexandru N, Constantinescu E, Popov D (2006) Effect of gap junction uncoupler heptanol on resistance arteries activity in experimental models of diabetes, hyperlipemia and hyperlipemia-diabetes. Vasc Pharmacol 44: 513-518. [Crossref]

14. Leite R, Webb RC (2001) Increased dilator response to heptanol and octanol in aorta from DOCA-salt-hypertensive rats. Pharmacology 62: 29-35. [Crossref]

15. Trosko JE1 (2011) The gap junction as a "Biological Rosetta Stone": implications of evolution, stem cells to homeostatic regulation of health and disease in the Barker hypothesis. J Cell Commun Signal 5: 53-66. [Crossref]

16. Garfield RE, Kanna MS, Daniel EE (1980) Gap junction formation in myometrium: Control by estrogens, progesterone, and prostaglandins. Am J Physiol 238: C81-C89. [Crossref]

17. Morand I, Fonlupt P, Gurrier A et al. (1996) Cell-to-cell communication in the anterior pituitary: Evidence for gap junction-mediated exchanges between endocrine cells and folliculo-stellate cells. Endocrinology 137: 3356-3367. [Crossref]

18. Gudoshnikov VI (1992) [The cytoarchitectonics of the adenohypophysis in light of the concepts of cellular flows]. Zh Obshch Biol 53: 790-796. [Crossref]

19. Goudochnikov VI (1998) Cytodifferentiation in anterior pituitary gland and the phases of postnatal development. Folia Endocrinol. Japon. 74: 424.

20. Meda P, Vozzi C, Ullrich S (1995) Gland cell connexins. Prog Cell Res 4: 281-287.

21. Fedotov VP, Baranova IN, Gudoshnikov VI (1990) [The effect of dibutyryl derivatives of cyclic nucleotides on albumin production in a primary culture of rat liver cells]. Vopr Med Khim 36: 69-72 (in Russian). [Crossref]
22. Gudoshnikov VI, Baranova IN, Fedotov VP (1991) Effect of dibutyryl derivatives of cyclic nucleotides on total RNA and protein synthesis in rat fetal hepatocyte cultures. Biull Eksp Biol Med 111: 616-618. [Crossref]

23. Gudoshnikov VI, Fedotov VP (1990) [Analysis of distribution by molecular weight of biologically active compounds, with possibility for their penetration through the gap junction channels taken into account. Izvestia Akad. Nauk Ser. Biol. 4: 622-625 (in Russian). [Crossref]

24. De Mello WC (1993) The cardiac renin-angiotensin system: Its possible role in cell communication and impulse propagation. Cardiovasc Res 29: 730-736. [Crossref]

25. De Mello WC (1996) Impaired regulation of cell communication by beta-adrenergic receptor activation in the failing heart. Hypertension 27: 265-268. [Crossref]

26. Evans WH, Martin PE (2002) Gap junctions: structure and function (Review). Mol Membr Biol 19: 121-136. [Crossref]

27. Loewenstein WR (1968) Emergence of order in tissues and organs: Communication through gap junctions. Implications in growth control and differentiation. Dev Biol 2: 268-291.

28. Meda P (1995) Junctional coupling of pancreatic beta-cells. In: Huizinga JD (Ed.) Pacemaker Activity and Intercellular Communication. Boca Raton: CRC Press: 275291

29. Fedotov VP, Gudoshnikov VI, Mamayeva TV (1994) [Role of calcium ions and cyclic nucleotides in the regulation of somatotroph functional activity in rats of different ages]. Probl Endokrinol (Mosk) 41: 42-45. [Crossref]

30. Levin M (2007) Gap junctional communication in morphogenesis. Prog Biophys Mol Biol 94: 186-206. [Crossref]

31. Spray DC, Rozental R, Srinivas M (2002) Prospects for rational development of pharmacological gap junction channel blockers. Curr Drug Targets 3: 455-464. [Crossref]

32. Garcia-Dorado D, Inserte J, Ruiz-Meana M, González MA, Solares J, et al. (1997) Gap junction uncoupler heptanol prevents cell-to-cell progression of hypercontracture and limits necrosis during myocardial reperfusion. Circulation 96: 3579-3586. [Crossref]

33. Bostanci MO, Bagirici F (2006) The effects of octanol on penicillin induced epileptiform activity in rats: An in vivo study. Epilepsy Res. 71: 188-194. [Crossref]

34. Saffitz JE (2000) Regulation of intercellular coupling in acute and chronic heart disease. Braz J Med Biol Res 33: 407-413. [Crossref]

Copyright: (C2019 Goudochnikov VI. This is an open-access article distributed under the terms of the Creative Commons Attribution License, which permits unrestricted use, distribution, and reproduction in any medium, provided the original author and source are credited. 